\title{
EFEITOS DA MORFOLOGIA SOBRE A COBERTURA PEDOLÓGICA NO MUNICÍPIO DE VERA - MT
}

\author{
Ivaniza de Lourdes L. Cabral* \\ Gilmar Ferreira da Silva**
}

\begin{abstract}
RESUMO
Concebendo solos como o produto resultante da interação entre o material de origem, relevo, clima, organismos vivos e tempo, tem-se o reconhecimento da extrema importância do fator relevo nos processos de origem e desenvolvimento do perfil pedológico. Sistemas de solos devem ser entendidos como unidades funcionais e de processos interagidos sob as mais variadas condições, dentre as quais estão as formas topográficas. O relevo, indicando a sua condição evolutiva, possibilita estabelecer inúmeros mecanismos que levam a uma maior ou menor "estabilidade" em termos de ação da água no interior das superfícies, fato denominado de processos pedogenéticos. A análise do efeito da morfologia sobre a cobertura pedológica apresentada teve como ponto de partida a distribuição espacial das variações pedológicas em relação à dimensão interfluvial, ao entalhamento dos rios e aos tipos de vales, a partir da compreensão da maior ou menor permanência da água nos componentes superficiais. O presente trabalho combina procedimentos de campo com análises de laboratório (análises texturais). Os resultados obtidos mostram que as formas de relevo muito amplas permitem maior ação da água no meio, dando condições para ocorrência de Latossolos Vermelho/Amarelo e Amarelo, enquanto os interflúvios de dimensões médias e/ou pequenas denotam maior drenagem, ambiente dos Latossolos Vermelhos. Os solos Hidromórficos restringem-se aos fundos de vales onde a ação da água no meio é constante.
\end{abstract}

Palavras Chave: Variação de Latossolos; Morfopedologia; Dimensão interfluvial; município de Vera.

\begin{abstract}
The soil is the interaction product among source-rock, relief, climate, live organisms and time, showing the extreme importance of the relief feature in the genesis and evolution of the pedologic profile. Soil systems must be understood as functional unities generated by interactive processes under the most variables conditions and, among those, the topographic forms. The relief, indicating its evolutive condition, makes possible to establish a great number of mechanisms conducting to a higher or lower stability in function of the water actions and/or interactions inside surfaces, the pedogenetic processes. The analysis of the morphologic effects on the pedologic cover presented here has as starting point the understanding of the longer or shorter permanence of water in the superficial components, in function of the spatial distribution of the pedologic variations, interfluvial dimensions, rivers carving and types of valleys, combining field works with textural laboratorial analysis. The results obtained show that the ample relief landforms permit a more intense water action in the soil, making possible the occurrence of red-yellowed and yellow oxisols. By the other way, the intermediate and/or smaller interfluvial dimensions have better water drainage, the ideal ambient for the formation of red oxisols. The hydromorphic soils are restricted to the bottom of valleys in which the water action is constant.
\end{abstract}

Key-words: Oxisols variation; Morphopedology; Interfluvial dimension; Vera municipality. 


\section{INTRODUÇÃO}

Para estabelecer uma correlação entre os vários fatores responsáveis pela diversidade pedológica no bioma de interface entre o Cerrado e a Floresta Amazônica foi necessário tomar, em primeira instância, o contexto geral da concepção solo.

Considera-se solo como sendo um material mineral e/ou orgânico inconsolidado, poroso, finamente granulado, com natureza e propriedades particulares, herdadas da interação de processos pedogenéticos com fatores ambientais envolvendo as variáveis material de origem, clima, organismos vivos, relevo e tempo (Bigarella, 1996).

Os vários tipos inseridos na condição transicional de ambiente equatorial e tropical foram tratados aqui sob o contexto de interação dos fatores genéticos dos mesmos.

Desta forma, a enumeração das grandes unidades de solo presentes na paisagem do município de Vera - MT foi discriminada levandose em consideração determinados fatores de sua formação, principalmente a morfologia do relevo. Para isso, o limite físico considerado para a descrição teve como referência a região entre os paralelos $14^{\circ}$ e $12^{\circ}$ de latitude Sul. Esta faixa do território mato-grossense está inserida na unidade morfoestrutural da Bacia Sedimentar Parecis (Ross, 2005), que constitui as superfícies planas do conjunto das formas de relevo do Planalto e Chapada dos Parecis. Esta unidade morfológica é o produto de uma paisagem derivada de estruturas sedimentares Cretácicas que respondem por uma topografia de interflúvios muito planos e/ou ligeiramente convexos (Ross, op cit; Miranda \& Amorim, 2001).

Sob tal contexto, os processos pedogenéticos deste setor pré-amazônico estão associados aos grupos dos Latossolos e suas variações, dos Neossolos e dos Gleissolos. A unidade dos Latossolos aparece junto às formas do relevo de colinas amplas, médias e pequenas de topografia muito plana e plana. Estes solos se formam sob condições pedogenéticas relacionadas aos processos geoquímicos de superfície, principalmente à alitização (Toledo et al., 2001). Tão importante quanto a litologia da qual derivam estes solos é a condição topográfica, pois esta, em conjunto com o ambiente climático da região, permite o desenvolvimento de perfis espessos desta variedade.

Condicionados à presença de água, os solos da categoria Glei ocupam as superfícies junto aos sistemas de drenagem de maior ordem e, dependendo do grau de entalhe do sistema hídrico, este se destacará mais ou menos em termos de área. Pela condição topográfica que favorece a ação quase constante da água em seus interstícios, esta unidade pedológica apresenta horizonte Glei no lugar do horizonte $\mathrm{Bt}$ ou $\mathrm{Bl}$, podendo também se manifestar em áreas abaciadas e depressões onde o sistema de drenagem é precário.

Associados a um ambiente que favorece o desempenho do intemperismo químico nos componentes sedimentares que estruturam toda a região, os Latossolos são a resposta da interação dos elementos geradores dos mesmos, e a sua diversidade resulta da variação de um ou mais de seus componentes de formação.

Assim, na unidade da paisagem PréAmazônica, onde está estabelecido o município de Vera, o grupo dos Latossolos se manifesta inserido na sua própria condição de formação, ou melhor, de evolução, e a resposta é uma grande quantidade de nuances de vermelho e amarelo nos Latossolos desta unidade morfopedológica.

Os Neossolos Quartzarênicos são as unidades de solo que se manifestam relacionadas a determinadas condições litológicas e topográficas. Por isso, restringem-se a algumas manchas no setor norte do município, junto à divisa com a unidade cratônica.

O impacto da introdução de uma cultura como a soja em um meio com estes sistemas pedológicos esbarra primeiramente na própria condição de restrita fertilidade natural destes solos. Por serem derivados de estruturas litológicas antigas, muito desgastadas pelos processos físico-químicos, apresentam baixos índices dos componentes exigidos pelas culturas, necessitando, assim, de intervenções de correção. Por outro lado, a retirada da cobertura vegetal original expõe as superfícies a uma outra condição de umidade e temperatura, intensificando não só os processos pedogenéticos de alitização, como também os 

laminar (Cabral, 2007).

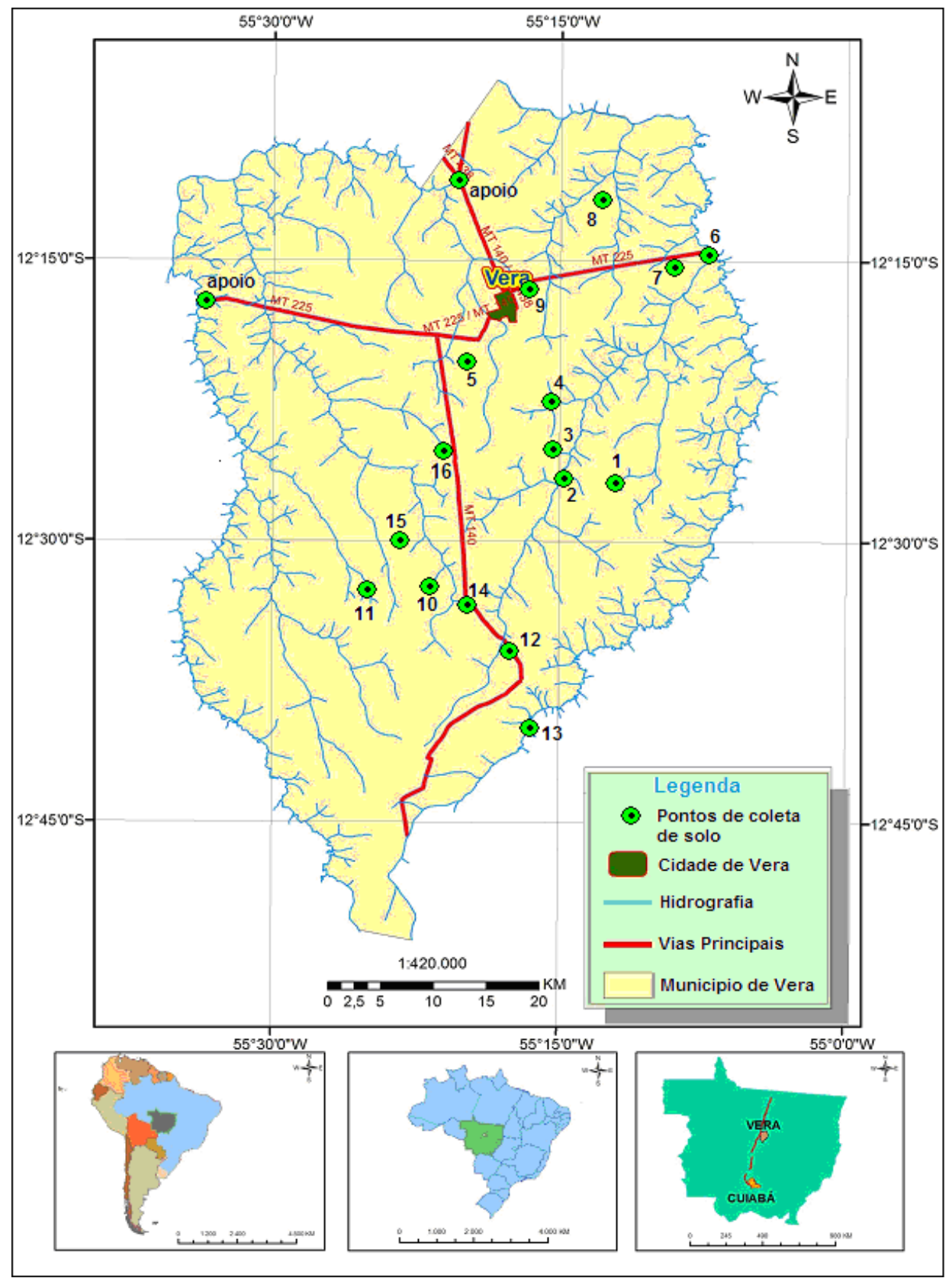

Figura 1 - Município de Vera/MT e os respectivos locais de onde foram retiradas amostras de solos. Fonte: SILVA, G. F (2008). 
Neste contexto, o trabalho tem por objetivo apresentar as relações existentes entre as variações dos Latossolos vermelho, amarelo e Glei no município de Vera - MT e as características do relevo, sob perspectiva da dinâmica hídrica nas diferentes unidades morfopedológicas.

Para isso, o trabalho levou em consideração as particularidades relacionadas às formas topográficas para estabelecer os diferentes setores morfológicos componentes do relevo, permitindo, posteriormente, interpretar as formas de ação da água nos diferentes setores topográficos que perfazem o conjunto morfopedológico da área em questão.

O município de Vera, com $2.951 \mathrm{Km}^{2}$ e 9.183 habitantes (IBGE, 2000), faz parte da microrregião homogênea de Sinop, constitui um dos municípios da frente de ocupação do agronegócio, expresso, num primeiro momento, pelas práticas da extração madeireira e, posteriormente, pela criação extensiva da pecuária de corte e agricultura. O município se situa entre as coordenadas de

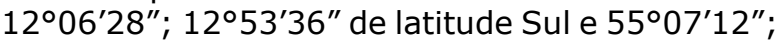
$55^{\circ} 50^{\prime} 24^{\prime \prime}$ de longitude Oeste, figura 1. Apresentase inserido na região climática equatorial do tipo quente e úmido com temperaturas médias superiores a $18^{\circ} \mathrm{C}$ e índices pluviométricos médios anuais acima de $2.000 \mathrm{~mm}$, distribuídos durante nove meses do ano, ou seja, nesta parte do estado ocorrem três meses de seca, durante os meses de julho, agosto e setembro (Maitelli, 2005).

Quanto à cobertura vegetal, a referida área pertence ao Bioma de Transição entre as formas fitoecológicas da Amazônia e Cerrado, predominando espécies tanto de um como do outro ecossistema, como por exemplo, Jacareúba, Ipê amarelo, Babaçu, Mogno e várias outras.

\section{METODOLOGIA}

Para atender à temática e aos objetivos propostos, o trabalho teve como suporte básico de investigação científica a abordagem geossistêmica, pois a temática em questão exige um instrumento lógico que possibilite a percepção das interdependências dos componentes físicos/ bióticos e das ações antrópicas que participam dos subsistemas ambientais aqui tratados (Sotchava, 1978; Christofoletti, 1980; Monteiro, 2000).

Baseada nesses autores, a presente abordagem evidencia as características referentes à interação indissociável dos elementos naturais, sociais e econômicos, responsáveis pelas diferentes paisagens que perfazem os espaços geográficos sob as diferentes perspectivas que as escalas analíticas permitem.

Em termos gerais, as regiões tropicais apresentam ambientes onde a energia solar incidente é bastante intensa sobre as camadas superficiais do relevo e os efeitos das condições climáticas vigentes promovem uma série de alterações em cadeia, interventoras nos fluxos funcionais dos sistemas e que se refletem numa série de eventos, dentre os quais estão as variações pedogeomorfológicas.

Assim, entendendo a indissociável interação e interdependência entre estes elementos, é que se chega ao contexto explicativo sobre a temática aqui pesquisada. Sendo assim, a abordagem geossistêmica contribuiu com a pesquisa ao possibilitar entendimento referente à dinâmica da natureza em termos de interação entre a evolução das formas do relevo e a diversificação dos grupo dos Latossolos no município de Vera- MT.

\subsection{Procedimentos: entendimento do registro cartográfico, distribuição espacial das variedades pedológicas e o detalhamento amostral - Análise física}

O entendimento geral da área e de sua função no sistema como um todo, deteve-se nas análises geológica, climática, pedológica, geomorfológica, fitoecológica e na evolução dos padrões de uso da terra, fornecidas em trabalhos como o do Projeto RADAMBRASIL (Brasil, 1986), Zoneamento Agroecológico do Estado de Mato Grosso (Sánchez, 1992), Sistema de Mapeamento Temático e Relatórios da SEPLAN (1997), entre outros.

Especificamente, o trabalho foi desenvolvido a partir do reconhecimento das variáveis do meio físico relevantes à avaliação da ação de infiltração 
da água nos sistemas de formação e transformação dos Latossolos, em superfícies com formas de relevo planas a muito planas. Essas variáveis foram identificadas e registradas por meio do mapeamento temático e com a elaboração de uma chave de identificação das três unidades pedológicas em questão.

Para identificar e locar as unidades pedológicas das variações dos Latossolos, como estabeleceu a presente proposta, primeiramente foi efetuado um trabalho de reconhecimento e ajuste da rede de drenagem, uma vez que este fato constitui o elemento chave que promove grande parte dos fatores que determinam a origem de cada unidade de solo a ser reconhecida.

Para isso foi estabelecida a correção da rede de drenagem pertencente ao município, tendo como base as cartas topográficas DSG, escala $1: 100.000$ e produtos do Sensoriamento Remoto Imagem de Satélite CBERS 2, Sensor CCD, escala $1: 100.000$, órbita ponto $114 / 166$ de agosto de 2007. O procedimento para obter as informações da rede de drenagem foi feito pela identificação não automatizada do objeto drenagem na imagem.

A elaboração desta base cartográfica permitiu obter o mapa dos interflúvios, sobre o qual todas as atividades relacionadas ao mapeamento das variedades de solo relacionadas ao relevo foram reconhecidas no município de Vera.

Todo esse trabalho teve como objetivo a representação cartográfica das subunidades morfológicas e a identificação dos processos de transformação do relevo para, em um segundo momento, fazer a análise dos pontos de baixa ou ausência da energia do relevo, ou seja, áreas de intenso processo químico e/ou físico, identificando e registrando as principais manifestações das transformações pedológicas vinculadas à presença da água em seu meio. Esse procedimento de registro cartográfico foi estabelecido com base nas cartas topográficas e produtos do sensoriamento remoto a exemplo do modelo digital do terreno.

Em relação aos aspectos físicos o primeiro procedimento foi o de obtenção das amostras. Estas foram retiradas de superfícies que apresentavam as variedades de solos a serem correlacionadas com o tipo de relevo, em lavouras com manejo convencional e plantio direto, utilizando um trado pedológico.

O procedimento de coleta levou em consideração a variação do Latossolo e a ação hidromórfica, pois estes fatos é que permitiram a visualização real das três unidades a serem consideradas. Para cada ponto foram retiradas duas amostras: de vinte e de quarenta centímetros de profundidade. Como o trabalho não visava à classificação dos solos e, sim, ao entendimento de como se articulam as variedades dos Latossolos com os tamanhos dos interflúvios, além deles apresentarem uma condição de certa "homogeneidade" nos aspectos físicos em termos de perfil, optou-se por trabalhar com amostras retiradas dos dois níveis de profundidade referenciados.

A análise granulométrica, para determinar a carga da calibragem do material na categoria argila, silte e areia, utilizou o método da pipeta, empregando $\mathrm{NaOH}$ a $1 \mathrm{~mol} \mathrm{~L}^{-1}$ como dispersante químico e submetendo à agitação mecânica em agitador "Stirrer" por 10 minutos, EMBRAPA (1997). Tais análises foram feitas no laboratório de solos da Universidade Federal de Mato Grosso.

\section{A INTERAÇÃO DOS FATORES DA PAISAGEM COM A VARIAÇÃO DOS SOLOS}

Sendo o solo uma entidade tridimensional, concebida pela ação dos fatores de formação e processos pedogenéticos, o seu conhecimento tem por princípio o entendimento destes fatores e, a partir daí, tem-se os meios para entender a formação e evolução dos perfis de solo nos mais diversos ambientes, ou seja, a compreensão do padrão de distribuição dos diversos solos na paisagem.

A transformação química, física, biológica e mineralógica dos constituintes dos solos é algo que não ocorre por acaso, mas que resulta da interação de, pelo menos, cinco fatores e/ou tipos de fatores: climáticos, biológicos, geomorfológicos (relevo), geológicos (material de origem) e o cronológico. Pelo processo de intemperismo, minerais primários são transformados e translocados dentro dos perfis de alteração, dando origem, conforme as condições 
vigentes, a uma vasta variedade de solos que compõem os diversos quadros de paisagem das diferentes unidades ambientais do planeta.

\subsection{Evolução das formas do relevo no meio tropical úmido}

Uma vez que a água, mediante precipitação líquida, atinge a superfície, duas situações podem se estabelecer em relação à maneira como esta se desloca para os locais receptores da mesma: a infiltração e o escoamento superficial.

A infiltração é o processo mais importante de reabastecimento de água no subsolo e, conforme Karmann (2001), o volume e a velocidade de infiltração dependem do tipo e das condições dos materiais terrestres, da cobertura vegetal, dos aspectos topográficos, dos índices pluviométricos e das formas de uso da terra.

A relevância deste fato se concretiza nas colocações de Karmann (op.cit), ao destacar que a zona de ocorrência de água subterrânea é uma região onde se desenvolve a maioria das formas de relevo, pois a água subterrânea é o principal meio das reações do intemperismo químico. Os produtos referidos correspondem aos processos de pedogênese, solifluxão, erosão interna solapamento e carstificação - dissolução e outros, apresentando, respectivamente, resultados como: cobertura pedológica, escorregamentos de encostas, voçorocas e relevo cárstico em sua ampla variedade de manifestações.

Ao agirem sobre as rochas, os agentes modificadores dão todas as condições para o estabelecimento do manto de alteração, composto pelos minerais primários inalterados e minerais secundários transformados e neoformados. As principais associações minerais presentes no manto de alteração são as micas, o quartzo, os argilominerais - caulinita e esmectita - e os oxi-hidróxidos de ferro e alumínio, além do complemento líquido composto de soluções aquosas ricas em sódio, cálcio, potássio, magnésio e, em menor escala, silício (Toledo et al., 2001).

Em síntese, a natureza dos minerais presentes e a sua textura/estrutura influem na alteração intempérica ao apresentarem, em termos de resistência, variabilidade quando sujeitos aos agentes transformadores. Nos meios alterados, essa variabilidade ocasiona a predominância de materiais mais resistentes, bem como a transformação ou o desaparecimento dos materiais que se alteram facilmente (Porto, 1996).

As reações químicas do intemperismo são mais intensas nas unidades de relevo que oferecem boas condições de infiltração de água. Estas condições estão relacionadas a relevos de platôs com encostas suaves, os quais permitem consideráveis índices de infiltração e relativa velocidade de deslocamento desta. Os produtos resultantes do intemperismo químico, em primeira instância, estão relacionados à formação e evolução dos perfis de solos - processos pedogenéticos - e, em condições excepcionais, que exigem uma conjunção de vários fatores, entre os quais condições agressivas de intemperismo, à formação de depósitos lateríticos.

Conforme Bigarella et al. (1996), a concepção de solo traz, intrinsecamente, a complexidade dos produtos resultantes do intemperismo químico. O solo, sob determinadas condições, se desenvolve de forma muito lenta sob a ação contínua dos agentes atmosféricos e biológicos. Na sua fase inicial de desenvolvimento prevalecem os processos físicos de fragmentação das rochas, hidratação dos minerais, além de outros processos químicos mais complexos, atingindo o ápice de desenvolvimento graças à atividade de organismos como líquens, crustáceos e microorganismos que se beneficiam dos nutrientes liberados na intemperização da rocha.

Os autores destacam que na camada alterada da rocha ocorre remoção dos elementos solúveis como o cálcio, sódio e outros, por ação das plantas e/ou lixiviação, enquanto se mantêm os minerais menos solúveis, como o magnésio, silício, ferro e alumínio. É a atividade complexa e conjunta dos fatores físicos, químicos e biológicos que possibilita o desenvolvimento da estrutura e do arranjo das partículas sólidas do solo e, consequentemente, a diversidade de tipos de solo.

Assim como a posição topográfica controla a formação de determinados oxissolos nos meios tropicais, o desenvolvimento de níveis concrecionários também está sujeito a esta questão. Bigarella et al. (op.cit) especificam que 
a origem dos oxissolos difere conforme a sua localização topográfica, ou seja, nas formas de relevo que caracterizam as chapadas, os oxissolos se formam pelas reações normais do intemperismo e pelos processos pedogenéticos, enquanto nas vertentes, devido a uma maior presença de umidade proveniente de superfícies superiores, apresentam elementos móveis liberados pelo intemperismo e que estão migrando com a água. Assim, o ferro e o manganês, por serem mais móveis que o alumínio, criam condições para que se estabeleça uma segregação lateral destes elementos, ou seja, o alumínio se concentrando mais nas chapadas, partes elevadas da topografia, o ferro na vertente abaixo e o manganês em superfícies bem inferiores, devido a sua maior mobilidade. A quantidade de ferro nas vertentes resulta da precipitação de compostos de ferro, sob forma cristalina e amorfa, nos vazios dos solos e dos depósitos coluviais das vertentes. Uma nova fase de dissecação do relevo pode levar à remobilização do ferro previamente depositado, dando origem a novos depósitos de ferro em superfícies topograficamente inferiores na vertente, além de possibilitar boa drenagem nestes.

Pedro \& Melfi (1983) apud Porto (1996) citam dois dos mecanismos básicos de evolução de perfis de alteração em regiões tropicais: (i) no qual as argilas cauliníticas mantêm-se associadas aos oxi-hidróxidos de ferro, formando um plasma homogêneo nas porções superiores do perfil, correspondendo à ferritilização geradora dos Latossolos típicos de ambientes permanentemente úmidos; e (ii) quando ocorre o inverso, ou seja, as argilas e os oxi-hidróxidos de ferro tendem a se separar levando à formação de níveis concrecionários ferruginosos e a uma maior diferenciação dos horizontes intempéricos, típico de processo de laterização, favorecido pelos regimes pluviométricos bem marcados em relação à alternância entre as estações seca e úmida.

Enfim, várias situações levam à precipitação e à formação de horizontes com concentração de determinados elementos. No caso do elemento ferro, qualquer que seja a fonte, este tende a se depositar na parte superior do lençol freático, onde tem lugar a oxidação dos compostos ferrosos em férricos (Bigarella et al., op.cit).

\subsection{Geomorfologia aplicada aos estudos pedológicos}

Relacionadas à ação física dos agentes modeladores, a sequência evolutiva das formas do relevo apresenta, na "paisagem", várias particularidades que não estão vinculadas somente ao comportamento destes agentes, mas também aos próprios elementos componentes das superfícies continentais do globo. Estas manifestações se apresentam diretamente associadas ao ambiente climático em vigor e, conforme as suas características, estarão prevalecendo, além das situações simultâneas, os processos vinculados à meteorização química em relação à física e vice-versa (Birkeland, 1974; 1984).

Em relação às formas de relevo e ao desenvolvimento dos solos, são indissociáveis os vários aspectos neles presentes, da sua superfície geomórfica. Os contínuos ciclos de construção, destruição e reconstrução das superfícies resultam em diferentes formas topográficas reveladoras dos fatores que fizeram e fazem parte da sua evolução. As colocações de Azolin (1975) sobre a análise evolutiva das formas de relevo para o estudo das características, da distribuição e do mapeamento de solos são importantes, pois apresentam resultados interessantes sobre a relação entre a distribuição dos solos com as superfícies geomórficas em perfis de solo e a superfície geomórfica na Depressão Periférica Gaúcha. Nelas o autor conclui que há uma boa correlação entre o desenvolvimento dos solos com a forma de relevo, ou seja, os solos menos evoluídos encontram-se na porção menos estável da vertente, as encostas e os mais desenvolvidos, na porção mais estável do relevo - topos das "coxilhas".

Carvalho et al. (1985) também desenvolveram trabalho de interação entre tipos de solo e relevo. Neste caso, os critérios de correlação adotados não foram, especificamente, em relação à forma do relevo e, sim, em relação às características das redes de drenagem com a natureza e propriedades dos solos, tendo como linha mestra a infiltração e o deflúvio entre unidades hidrográficas com diferentes formas. 
Na mesma linha de trabalho, Palmieri \& Larach (1996) deixam claro que as correlações entre a configuração do terreno e as classes de solos são válidas para condições fisiográficas específicas, pois as características do relevo local exercem influência nas condições hídricas e térmicas dos solos, as quais irão se refletir nas condições de microclima, na natureza da vegetação original e nas próprias características e propriedades dos solos. Assim, propriedades como a dinâmica da água, a espessura do perfil de solo e diferenciação de horizontes, horizonte superficial, espessura e teor de matéria orgânica, cor e temperatura do solo, saturação de bases e lixiviação são atributos do solo inerentes ao relevo.

Sobre este assunto, Queiroz Neto (2000), com base em uma ampla análise literária, destaca que o papel da pedogênese na evolução do relevo é algo intrínseco à própria evolução morfogenética, evidenciando a interação entre estas duas áreas do conhecimento científico.

Rosseti (1970), apud Palmieri \& Larach (1996), destaca que a posição topográfica em conjunto com a declividade, ruptura de declive e outros fatores constituem indicadores seguros sobre diferentes tipos de solos, ou seja, o relevo é um elemento de primeira instância para reconhecimento e identificação dos solos, independente da escala de levantamento, assim como o mediador das interferências que visam a manutenção e preservação dos mesmos.

Aplicando os princípios da morfopedologia para análise integrada dos condicionantes físicobióticos geradores de processos da dinâmica superficial em bacia hidrográfica, Vasconcelos (1998) considera as variações nas formas das vertentes um elemento relevante em termos de cobertura pedológica e fitofisionômica.

Nesta questão, Nascimento \& Perez (2003) destacam que os "sistemas de solos", compreendidos sob a perspectiva de unidades funcionais e de processos, formam a base que constitui o parâmetro de delimitação das unidades geo-ambientais que, em termos práticos apresentam um conteúdo de aplicação, principalmente no que se refere à utilização das superfícies (Hermuche et al, 2009).

Finalmente, devido à ênfase dada em relação aos problemas ambientais, este assunto tem recebido enorme incremento de obras que, segundo Vidal Torrado (1994) receberam na língua inglesa o nome de "Soil Geomorphology" (Daniels \& Hammer, 1992; Gerrard, 1992). A expressão significa "Relações Solo-Geomorfologia" ou "Relações Pedologia-Geomorfologia" para os temas de trabalhos que pesquisam sobre as relações entre os solos, as superfícies geomórficas que ocupam e os materiais geológicos dos quais derivam.

\section{RESULTADOS E DISCUSSÕES}

Os elementos formadores dos sistemas morfopedológicos no município de Vera apresentamse em constante transformação, a qual pode ser detectada sob as mais variadas formas e escalas de análise. Para isso, o referencial na tomada de decisões, para o levantamento das informações e de algumas análises, baseou-se no objetivo do trabalho de verificar a relação morfológica com a variação pedológica.

\subsection{O relevo: os elementos morfológicos e sua dinâmica}

O levantamento geomorfológico do município de Vera constituiu um estudo integrado da morfologia/densidade de cursos d'água e dos processos modeladores do relevo, objetivando a caracterização topográfica da área, e servindo de base para a definição das superfícies com a presença de Latossolos Vermelho, VermelhoAmarelo e Amarelo e os solos hidromórficos - Gleis e Planossolos. Para isso foram definidas, com base nas análises das dimensões dos interflúvios, as superfícies morfológicas com suas respectivas variedades pedológicas.

Assim, no contexto geral da escala adotada no trabalho, $1: 100.000$, verificou-se que a distribuição das dimensões dos interflúvios, devido ao próprio controle estrutural regional, expressa valores diferentes conforme a orientação dos principais pontos cardeais. Tomando as medidas transversais no sentido leste-oeste temos as maiores dimensões, com médias em torno de 
2.550 metros de largura. Entretanto, partindo para uma avaliação das dimensões dos interflúvios no sentido norte-sul, os valores médios destes diminuem quase pela metade, ou seja, 1.740 metros, representando a superfície mais dissecada e drenada do município.

Em termos pedológicos e da própria evolução das superfícies morfológicas do município, essas informações são de extrema importância, uma vez que tais dados sustentam as interpretações da dinâmica da água nos componentes superficiais de cada tipo morfológico, em termos de sua dimensão. Fato que se reflete nas condições pedológicas local e regional.

Com base nesta constatação, as superfícies que apresentam as maiores dimensões, em torno de 2.550 metros ou mais, por terem condições de pouca drenagem, fazem com que a água atue por mais tempo no meio pedológico/ geológico, denotando características claras da ação hidromórfica em superfícies relativamente elevadas na região.

O esquema da Figura 2 mostra as manifestações dos tipos de solos associados aos interflúvios de grandes dimensões. Nesta categoria, percebe-se que os Latossolos VermelhoAmarelo e Amarelo ocupam as superfícies de topos muito amplos onde as condições de drenagem são deficitárias. Já os Latossolos Vermelhos estão, quando as condições de declividade permitem, no setor de borda destes amplos interflúvios, pois esta é a superfície onde estão situados os tributários dos principais eixos de drenagem, os quais permitem melhores condições de drenagem.

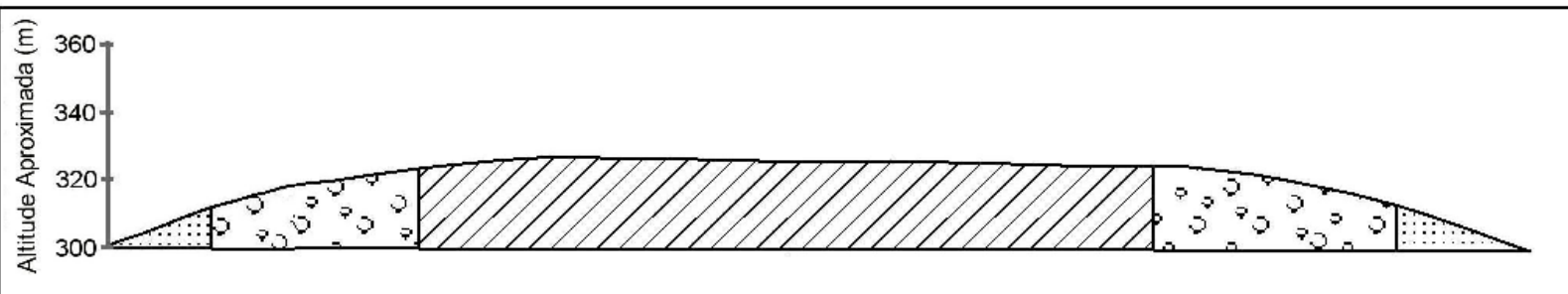

Legenda

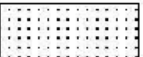

Fundo de vales: superfície pouco drenada com solos hidromórficos (Gleis e Planossolos).

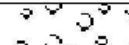

Superfície de dissecação: área bem drenada com latossolo vermelho.

Superfície interfluvial: área pouco drenada com latossolos vermelho-amarelo e amarelo.

Figura 2 - Aspecto morfológico de interflúvio amplo ( $2550 \mathrm{~m}$ ) e a variação pedológica no município de Vera - MT. Medida e observação dos interflúvios no sentido leste-oeste.

Fonte: Levantamento de campo, Cartas topográficas DSG, escala 1:100.000 e Imagem de Satélite CBERS 2, Sensor CCD, escala 1:100.000, órbita ponto 114/166 de agosto de 2007.

Nesta unidade de compartimentação do relevo, assim como na outra a seguir, os solos hidromórficos (Gleis e Planossolos) estarão sempre condicionados ao entalhe dos principais eixos de drenagem, pois nestas superfícies, devido à própria condição topográfica, é que se encontram todas as condições de umidade que permitem o desenvolvimento de tais unidades de solos. 
O esquema da Figura 3 apresenta a situação das manifestações pedológicas em interflúvios médios ( $1740 \mathrm{~m}$ ) e/ou de pequena dimensão (< $700 \mathrm{~m}$ ). Nesta situação, os Latossolos Vermelhos estão ocupando todo o interflúvio, uma vez que estes oferecem boas condições de drenagem, indicando menor permanência da água em seus interstícios. Portanto, esta é a superfície com menor ataque hidromórfico de toda a área em questão.

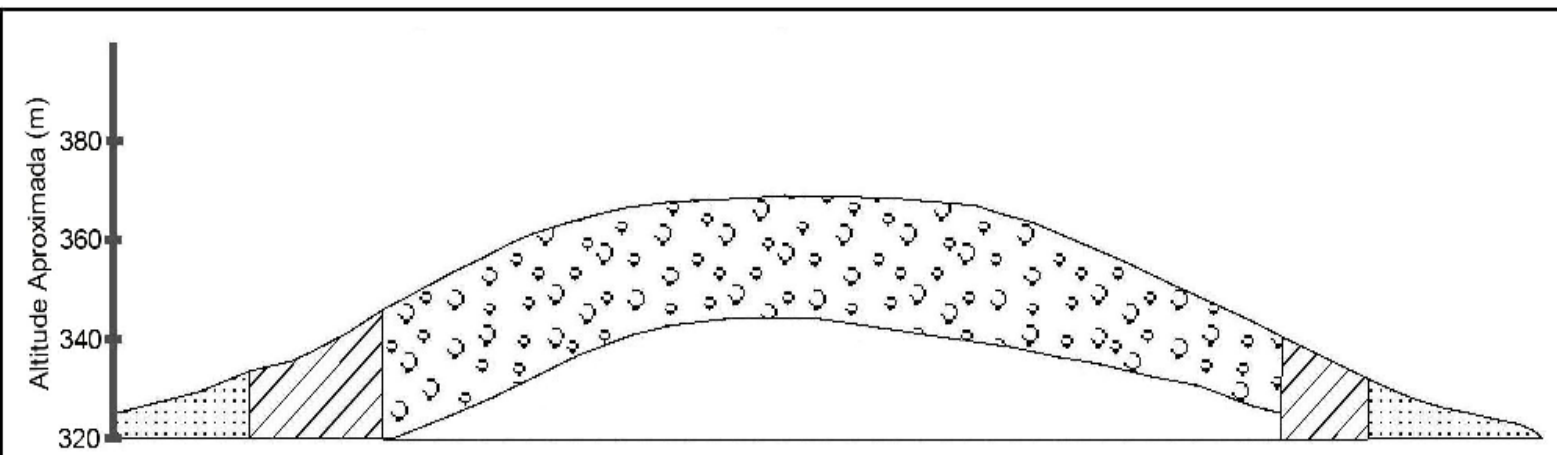

\section{Legenda}

Fundo de vales: superfície pouco drenada com solos hidromórficos (Gleis e Planossolos).

Superfície interfluvial: área bem drenada com latossolo vermelho.

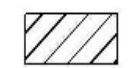

Superfície de contato entre topo de colina e fundo de vale: área pouco drenada com latossolos vermelho-amarelo e amarelo.

Material subjascente: Grupo Parecis.

Figura 3; Aspecto morfológico de interflúvio médio ( $1740 \mathrm{~m}$ ) e/ou pequeno $(<700 \mathrm{~m}$ ) e a variação pedológica no município de Vera - MT. Medida e observação dos interflúvios no sentido norte-sul.

Fonte: Levantamento de campo, Cartas topográficas DSG, escala 1:100.000 e Imagem de Satélite CBERS 2, Sensor CCD, escala 1:100.000, órbita ponto 114/166 de agosto de 2007.

Na situação da Figura 3, para interflúvio médio e/ou pequeno, os Latossolos Vermelhos ocupam as superfícies de topo, os Latossolos Vermelho-Amarelo e Amarelo, quando a declividade permitir, ou seja, diminuir muito, mas não o suficiente para permitir a presença constante da água, estarão nas superfícies intermediárias entre os Latossolos Vermelhos e os solos Hidromórficos
(Gleis e Planossolos).

Comparando as duas situações, em termos gerais ocorre uma inversão na posição morfológica das variedades pedológicas, conforme a amplitude dos interflúvios. Na situação da Figura 2, interflúvios amplos, os Latossolos Vermelho-Amarelo e Amarelo ocupam a posição de topo, enquanto 
que os Latossolos Vermelhos, as superfícies mais drenadas e com uma pequena declividade, e os solos Hidromórficos (Gleis e Planossolos), as superfícies junto aos principais eixos de drenagem.

\subsection{Os tipos de vertentes, suas inclinações e o aspecto textural dos solos.}

No contexto geral da área, as superfícies que compõem o relevo do município apresentam declividades muito baixas, restringindo-se praticamente às superfícies de entalhamento das drenagens. Essa característica permite uma condição de "estabilidade", em que a drenagem interna favorece os processos pedogenéticos que se apresentam distribuídos ao longo dos interflúvios, ocupando grande parte das superfícies mais elevadas do município e adjacências. A condição de muito baixa declividade é que possibilita a ocorrência das variações pedológicas citadas para a referida área, pois esse fato afeta diretamente a forma e a velocidade de deslocamento das águas e, consequentemente, as características dos solos.

Em termos de condições texturais para melhor caracterizar as variações dos solos presentes nas diferentes superfícies, considerando os interflúvios amplos, médios e pequenos, foram tomadas algumas amostras de solos de 16 pontos distintos, conforme representado na figura 1 . Os resultados das análises, tabelas I, II e III, apresentam uma variação dos componentes sólidos das amostras de solo retiradas, na variação Latossolo Vermelho-Amarelo e Amarelo, Latossolo Vermelho e solos Hidromórficos (Gleis e Planossolos).

Tabela I - Características físicas de amostras de Latossolos Amarelo no município de Vera - MT.

\begin{tabular}{|c|c|c|c|c|c|c|}
\hline \multirow{2}{*}{$\begin{array}{c}\text { Pontos } \\
\mathrm{Na} \\
\text { figura } 1\end{array}$} & \multirow{2}{*}{$\begin{array}{c}\text { Categoria } \\
\text { de solo }\end{array}$} & \multirow{2}{*}{$\begin{array}{c}\text { Situaça / } \\
\text { Alt (m) }\end{array}$} & \multirow{2}{*}{$\begin{array}{l}\text { Prof. } \\
\text { (cm) }\end{array}$} & \multicolumn{3}{|c|}{ Resultados Analíticos } \\
\hline & & & & Argila $(\%)$ & Silte $(\%)$ & Areia $(\%)$ \\
\hline \multirow{2}{*}{5} & $\mathrm{LA}$ & Floresta/ & 20 & 722 & 08,1 & 19.8 \\
\hline & YR $7 / 6$ & & 40 & 73,8 & 09,8 & 16,4 \\
\hline \multirow{2}{*}{11} & $\mathrm{LA}$ & Lavoura/ & 20 & 55,5 & 09,8 & 34,7 \\
\hline & YR 6/8 & 382 & 40 & 68,8 & 01,4 & 29,8 \\
\hline \multirow{2}{*}{15} & $\mathrm{LA}$ & Floresta/ & 20 & 58,8 & 01,4 & 39,8 \\
\hline & $\mathrm{YR} 5 / 4$ & 389 & 40 & 58,8 & 04,8 & 36,4 \\
\hline \multirow{2}{*}{16} & $\mathrm{LA}$ & Lavoura/ & 20 & 55,5 & 04,8 & 39,8 \\
\hline & YR 7/8 & 395 & 40 & 68,8 & 04,8 & 26,4 \\
\hline
\end{tabular}

Fonte: Levantamento de Campo (Abril de 2007). Análise de laboratório - Laboratório de solos . Dep. de solos da UFMT. 
Tabela II - Características físicas de amostras de Latossolos Vermelho e Vermelho-Amarelo no município de Vera - MT.

\begin{tabular}{|c|c|c|c|c|c|c|}
\hline \multirow{2}{*}{$\begin{array}{c}\text { Pontos } \\
\text { na } \\
\text { figura } 1\end{array}$} & \multirow{2}{*}{$\begin{array}{c}\text { Categoria } \\
\text { de solo }\end{array}$} & \multirow{2}{*}{$\begin{array}{c}\text { Situação / } \\
\text { Alt (m) }\end{array}$} & \multirow{2}{*}{$\begin{array}{l}\text { Prof. } \\
(\mathrm{cm})\end{array}$} & \multicolumn{3}{|c|}{ Resultados Analíticos } \\
\hline & & & & Argila (\%) & Silte (\%) & Areia (\%) \\
\hline \multirow{2}{*}{1} & $\overline{L V}$ & Lavoura / & 20 & 68,8 & 11,4 & 19,8 \\
\hline & YR 5/6 & 361 & 40 & 72,2 & 08,1 & 19,8 \\
\hline \multirow{2}{*}{7} & LVA & Lavoura / & 20 & 58,8 & 09,8 & 31,4 \\
\hline & YR 5/8 & 359 & 40 & 65,5 & 01,4 & 33,1 \\
\hline \multirow{2}{*}{3} & LV & Lavoura / & 20 & 35,5 & 01,4 & 63,1 \\
\hline & YR 5/8 & 365 & 40 & 42,2 & 06,4 & 51,4 \\
\hline \multirow{2}{*}{14} & LV & Lavoura / & 20 & 58,8 & 01,4 & 39,8 \\
\hline & R 5/4 & 352 & 40 & 68,8 & 01,4 & 29,8 \\
\hline \multirow{2}{*}{12} & LVA & Roçado / & 20 & 12,2 & 28,1 & 59,8 \\
\hline & YR 5/8 & 369 & 40 & 40,5 & 03,1 & 56,4 \\
\hline \multirow{2}{*}{10} & LV & Lavoura / & 20 & 47,2 & 23,1 & 29,8 \\
\hline & YR 5/6 & 400 & 40 & 68,8 & 04,8 & 26,4 \\
\hline \multirow{2}{*}{8} & LVA & Lavoura / & 20 & 62,2 & 04,8 & 33,1 \\
\hline & YR 5/6 & 378 & 40 & 65,5 & 04,8 & 29,8 \\
\hline \multirow{2}{*}{9} & LV & Lavoura / & 20 & 35,5 & 01,4 & 63,1 \\
\hline & YR 5/8 & 365 & 40 & 42,2 & 06,4 & 51,4 \\
\hline
\end{tabular}

Fonte: Levantamento de Campo (Abril de 2007). Análise de laboratório - Laboratório de solos . Dep. de solos da UFMT.

Tabela III - Características físicas de amostras de solos Hidromórficos - Gleis e Neossolos Quartzarênicos no município de Vera - MT.

\begin{tabular}{c|c|c|cc|c|c}
\multirow{2}{*}{$\begin{array}{c}\text { Pontos } \\
\text { Na } \\
\text { figura 1 }\end{array}$} & Categoria & Situação / & Prof. & \multicolumn{3}{c}{ Resultados Analíticos } \\
\cline { 6 - 7 } & de solo & Alt (m) & $(\mathrm{cm})$ & Argila (\%) & Silte (\%) & Areia (\%) \\
\hline \multirow{2}{*}{4} & G e NQ & Mata Ciliar / & 20 & - & - & - \\
& YR 5/3 & 323 & 40 & 15,5 & 08,1 & 76,4 \\
\multirow{2}{*}{13} & G & Mata Ciliar / & 20 & 55,5 & 04,8 & 39,8 \\
& Y 5/1 & 367 & 40 & 68,8 & 04,8 & 26,4 \\
\hline \multirow{2}{*}{2} & NQ & Mata Ciliar / & 20 & 02,2 & 01,4 & 96,4 \\
& YR 5/2 & 346 & 40 & 05,5 & 16,4 & 78,1 \\
\hline \multirow{2}{*}{6} & G e NQ & próximo a & 20 & 12,2 & 01,4 & 86,4 \\
& YR 6/4 & Mata Ciliar / & 20 & 13,8 & 04,8 & 81,4 \\
\hline
\end{tabular}

Fonte: Levantamento de Campo (Abril de 2007). Análise de laboratório - Laboratório de solos. Dep. de solos da UFMT. 
Os valores apresentados na Tabela I, embora representem apenas alguns pontos de amostragem, revelam uma certa variação nas características dos solos que compõem praticamente todo o setor de nascentes da área pesquisada. Esta variação está relacionada ao comportamento clinográfico das três principais sequências de formas de vertentes que fazem parte do conjunto do relevo em geral.

Os índices clinográficos bastante baixos nas superfícies divisoras de águas estabelecem condições que, em geral, viabilizam a atividade pedogenética nos setores mais elevados do terreno, fato, de certo modo, revelado pelas próprias características dos componentes físicos nas superfícies de topo e das pequenas encostas.

Assim, conforme os dados a respeito da análise física das três variedades de solos consideradas, observa-se que os materiais relacionados aos Latossolos Vermelho, VermelhoAmarelo e Latossolos Amarelos, Tabelas I e II, expressam materiais com condições físicas argiloarenosas, característica peculiar dos Latossolos.

Comparando a variação destes componentes entre as variações de Latossolo Vermelho e Vermelho-Amarelo com os Latossolos Amarelos, nota-se que o material deste último apresenta índice maior para a componente argila e uma pequena diminuição no componente areia, ou seja, o Latossolo Amarelo é um material mais argiloso do que o Latossolo Vermelho e Vermelho-Amarelo, comprovando a maior ação hidromórfica nestes, devido às suas condições de baixa drenagem.

Em relação aos solos constantemente sujeitos à ação da água - solos hidromórficos, Gleis, Planossolos e Neossolos Quartzarênicos, Tabela III, a análise apresentou resultados expressando, na sua maioria, condições de lixiviação intensa, onde o componente areia prevalece em quase todas as amostras. Esse fato está relacionado à própria condição morfológica de sua ocorrência.

Neste setor do terreno a ação da água no meio geológico/pedológico ocorre sob várias formas e, conforme as condições do perfil longitudinal das unidades de drenagem, pode-se ter melhor clareza da distribuição geográfica destes na paisagem, pois os solos hidromórficos, Gleis e Planossolos apresentam uma dinâmica pedogenética diferente dos Neossolos Quartzarênicos, os quais estão vinculados aos processos de transporte e deposição mecânica, relacionados com os eventos de cheia dos rios de maior ordem hierárquica.

Enfim, estes dados expressam as características físicas das variações de solos correlacionadas com as suas condições de relevo, o que não deixa, de certo modo, de apresentar as condições da ação da água em seu meio e com isso a própria dinâmica de desenvolvimento pedológico e morfológico no município de Vera - MT.

\section{CONSIDERAÇÕES FINAIS}

A presente análise mostra que a distribuição dos solos no município de Vera - MT está interrelacionada aos aspectos morfológicos de colinas muito amplas, colinas médias e/ou pequenas e fundos de vales nas suas diversas manifestações.

Esse tipo de análise é interessante, pois permite obter a distribuição geográfica dos solos de uma determinada área, numa escala de semidetalhe para subsidiar trabalhos não só de mapeamento detalhado de solos, mas também para auxiliar as tomadas de decisões no que se refere às ações de planejamento para as mais diversas finalidades. Além do mais esse tipo de entendimento permite uma maior compreensão dos processos de evolução do relevo, principalmente em locais de "estabilidade geológica".

A análise da relação entre as formas topográficas e a variação dos solos no município de Vera - MT, sob escala de semidetalhe revelou que há uma estreita interação entre a dimensão interfluvial e a variação dos Latossolos, ou seja, Latossolos Vermelho - Amarelo e Amarelo em interflúvios muito amplos e Latossolos Vermelho em interflúvios médios e/ou pequenos.

A distribuição e a maneira como os Latossolos e os Solos Hidromórficos - Gleis, Planossolos e Neossolos Quartzarênicos se apresentam conduzem ao entendimento da ação geoquímica nos componentes sedimentares que compõem esse setor do Planalto e Chapada dos Parecis em Mato Grosso, relacionados às várias modalidades de ação da água na transformação destas superfícies. 


\section{Autor Colaborador}

Claudinei Marcelo Salgado - Dep. de Geografia/
ICHS/UFMT- Programa de Pós-Graduação - Mestrado em Geografia / UFMT.

\section{Bibliografia}

AZOLIN, M. A. D. Relações solo - superfícies Geomórficas e material de origem a oeste da Depressão Central e Campanha no Rio Grande do Sul. Faculdade de Agronomia - UFRGS. Porto Alegre - RS. Dissertação de Mestrado. 1975.

BIGARELLA, J. J; BECKER, R. D \& PASSOS. Estrutura e origem das paisagens tropicais e subtropicais. Florianópolis: Editora da UFSC, 1996.

BIRKELAND, P. W. Pedology, Weathering and Geomorphological Research. New York: Oxford University Press, 1974.

Soils and Geomorphology. New York, Oxford Univ. Press, 1984.

BRASIL Ministério das Minas e Energia - Secretaria Geral. Projeto Radambrasil. Folha SD 21 - Cuiabá; Geologia, Geomorfologia, Pedologia, Vegetação e Uso Potencial da terra. Volume 26. Rio de Janeiro, 1986.

CABRAL, I. L.L. Aspectos físico-químicos de Latossolos Vermelho, Amarelo e Glei, em área com e sem a cultura da soja. In: Expansão da Soja na Pré-Amazônia Mato-Grossense: Impactos Socioambientais. Gilda Tomasini Maitelli e Cleusa Aparecida Gonçalves Pereira Zamparoni (Organizadoras). Cuiabá - MT: Entrelinhas: EdUFMT, 2007.

CARVALHO, W. A; PIEDADE, G. C. R; MORAES, M H \& ONUMA, P. Y. Similaridade geométrica de bacias hidrográficas e o mapeamento de solos. Revista de Geografia. São Paulo: UNESP. Volume 4, 1985.

CHRISTOFOLETTI, A. Geomorfoloogia Fluvial. São Paulo: Edgard Blücher, 1981.

Modelagem de Sistemas Ambientais. São
Paulo: Edgard Blücher, 1999.

DANIELS, R. B. \& HAMMER, R. D. Soil Geomorphology. New York, John Wiley \& Sons, Inc. 1992.

EMBRAPA/BRASIL - EMPRESA BRASILEIRA DE PESQUISA AGROPECUÁRIA. Manual de Métodos de Análise de Solo. 2. ed. Rio de Janeiro: EMBRAPA Centro Nacional de Pesquisa de Solos, 1997.

GERRARD, J. Soil Geomorphalogy an integration of Pedology and Geomorphology. London, Chaman 7 Hall ed. 1992.

HERMUCHE, P. M; GUimARÃES, G. M. A \& CASTRO, S. S de. Análise dos compartimentos Morfopedológicos como subsídio ao planejamento do uso do solo em Jataí - Go. GEOUSP - Espaço e Tempo, São Paulo, No 26, 2009.

IBGE, Censo Demográfico (2000). Disponível em <http://www.ibge.gov.br/cidadesat> Acesso em novembro de 2008.

MAITELLI, G. T. Interações atmosfera - superfície. In: Geografia de Mato Grosso: Território, Sociedade, Ambiente. Gislaene Moreno e Tereza Cristina Higa (Organizadoras). Cuiabá: Entrelinhas, 2005.

MIRANDA, L \& AMORIM, L. Mato Grosso: Atlas Geográfico. Cuiabá: Entrelinhas, 2001.

MONTEIRO, C. A de F. Geossistemas: A História de uma Procura. São Paulo: Contexto, 2000.

NASCIMENTO, N. R. do e PEREZ, D. H. Evolução Pedomorfológica das vertentes em Conceição do Araguaia (PA): Abordagem metodológica e evidências macro e micromorfológicas. Revista Brasileira de Geomorfologia. Ano 4, No 1. 2003. 
KARMANN, I. Ciclo da água: Água subterrânea e sua ação geológica. In: Decifrando a Terra. Wilson Teixeira et al (Organizadores). Oficina de Textos, 2001.

PALMIERI, F \& LARACH, J. O. I. Pedologia e Geomorfologia. In: Geomorfologia e MeioAmbiente. Antonio José Teixeira Guerra e Sandra Baptista da Cunha (Organizadores). Rio de Janeiro: Bertrand Brasil, 1996.

PORTO, C. G. Intemperismo em regiões tropicais. In: Geomorfologia e Meio-Ambiente. Antonio José Teixeira Guerra e Sandra Baptista da Cunha (Organizadores). Rio de Janeiro: Bertrand Brasil, 1996.

QUEIROZ NETO, J. P. de. Geomorfologia e Pedologia. Revista Brasileira de Geomorfologia. Vol 1. № 1, (59-67). 2000.

ROSS, J. L. S. Geomorfologia Ambiental In: Geomorfologia do Brasil / Sandra Baptista da Cunha, Antonio José Teixeira Guerra (Organizadores). 3. ed. - Rio de Janeiro: Bertrand Brasil, 2003.

VASCONCELOS, T. N. N e CASTRO JUNIOR, P. R de. Estrutura e formas de Relevo. In: Geografia de Mato Grosso: Território, Sociedade, Ambiente. Gislaene Moreno e Tereza Cristina Higa (Organizadoras). Cuiabá: Entrelinhas, 2005.
SÁNCHEZ, R.O. Zoneamento agroecológico do Estado de Mato Grosso: Ordenamento ecológico paisagístico do meio natural e rural. Cuiabá - Mato Grosso. Fundação de Pesquisas Cândido Rondon, 1992.

SEPLAN - Secretaria de Estado de Planejamento e Coordenação Geral. Zoneamento Sócio Econômico - Ecológico do Estado de Mato Grosso. Cuiabá - MT: 2000.10 CD-ROM.

SILVA, G. F da. Geoprocessamento aplicado à interpretação das interações entre relevo e solo no município de Vera - MT. Dissertação de Mestrado. UFMT/Dep. de Geografia, 2008.

SOCTCHAVA, V. B. Por uma teoria de classificação de geossistemas de vida terrestre. Comunicação apresentada na Reunião do Setor de Problemas Físico-Geográficos Complexos. São Paulo: Universidade de São Paulo, 1978.

TOLEDO, M. C. M, O; OLIVEIRA, S. M. de \& MELFI, A. J. Intemperismo e formação do solo. In: Decifrando a Terra: Wilson Teixeira... et al (Organizadores). São Paulo: Oficina de Textos, 2001.

VIDAL TORRADO, P. Pedogênese e Morfogênese no distrito de Tupi - Piracicaba SP. Tese de Doutorado, Piracicaba, São Paulo, ESALQ. 1994. 